\title{
The Evolution of the Connotation of College Students' Information Literacy in the 5G Environment and the Cultivation Strategy
}

\author{
ZhiHong Ruan ${ }^{1,2,}{ }^{*}$, Rao Xiang ${ }^{1}$ and QianQian Weng ${ }^{1}$ \\ ${ }^{1}$ School of Education Science, Guizhou Normal University, Guiyang, Guizhou, China, 550001 \\ ${ }^{2}$ Research Center of Wisdom Education, Guizhou Normal University, Guiyang, Guizhou, China,550001 \\ ${ }^{*}$ Corresponding author. Email: small_russet@126.com
}

\begin{abstract}
With the advent of the $5 \mathrm{G}$ era, the connotation and cultivation of college students' information literacy have been given a new era connotation. This article sorts out the development path of information literacy of college students in my country under the $1 \mathrm{G}$ to $4 \mathrm{G}$ environment, and tries to propose the development direction and training strategies of college students' information literacy in the $5 \mathrm{G}$ era, so as to provide some references for college students to better face the new challenges of the $5 \mathrm{G}$ era.
\end{abstract}

Keywords: 5G, College Students, Information Literacy, Strategy

\section{INTRODUCTION}

"In the future, information literacy is the only lasting competitive advantage you have, perhaps the ability to learn faster than your competitors." ${ }^{[1]}$. The concept of "information literacy" was first put forward by Paul Zurkouski, then chairman of the American Information Industry Association in $1974^{[2]}$, and subsequent research has been carried out in full swing abroad.

Currently, 100,000 5G base stations have been built, and 5G application scenarios have entered people's lives. As the back wave of promoting social development, how should college students respond to the information wave in the $5 \mathrm{G}$ era? What are the characteristics of information literacy in the $5 \mathrm{G}$ environment? In view of this, this article hopes to sort out the development path of information literacy of Chinese college students in the $1 \mathrm{G}$ to $4 \mathrm{G}$ environment, and try to propose the development direction and training strategies of college students' information literacy in the $5 \mathrm{G}$ era, so as to better face the new challenges of the $5 \mathrm{G}$ era Provide some reference.

\section{THE DEVELOPMENT OF 1G TO 4G COLLEGE STUDENTS' INFORMATION LITERACY}

\subsection{G2G environment: cultivating college students' information retrieval ability}

In $1 \mathrm{G}$ and $2 \mathrm{G}$ environments, information channels are limited, the penetration rate of mobile devices is low, and information exchange is limited. At this stage, cultivating the information ability of college students is mainly to do exploratory work from the clarification of theoretical concepts to practical operation. Generally speaking, the "document retrieval" course is the main carrier and the goal is to "cultivating college students' information retrieval ability". Pursue the effectiveness of information. In 1992, the Ministry of Education issued the "Basic Requirements for the Teaching of Document Retrieval Courses", which required college students to learn computer-based document information retrieval and utilization to promote their own professional learning. Because of its rich resources such as academic literature, professional books, and hardware equipment, university libraries have become the undertakers of college students' information ability training. In the training process, computer-based literature information retrieval is an important content of course learning, and it pays particular attention to 
improving the information retrieval level of college students, highlighting the ability of college students to obtain and apply scientific research information, and embody the concept of "tool-based".

\subsection{Under the $3 G$ environment: improve the efficiency of college students' use of information}

The application of $3 \mathrm{G}$ technology has promoted the rapid popularization of broadband networks. Broadband network school-to-school communication has achieved basic coverage in colleges and universities, and massive multi-dimensional information has begun to access the network. As a group of new things, college students are keen to exchange information through social platforms. A single academic literature information retrieval can no longer meet the basic needs of college students, and the connotation of information literacy needs to be enriched. Scholars in pedagogy, computer science, library and information and other disciplines have started to discuss the connotation of information literacy. Among them, the four-element theory has the highest degree of recognition and acceptance, that is, information literacy is composed of information awareness, information knowledge, information ability, and information ethics ${ }^{[3]}$.The connotation of information literacy also expands from focusing on a single skill level to the personality psychological characteristics needed to complete information activities ${ }^{[4]}$.The information literacy of college students has actually changed from tool-based to ability-based. At this stage, information literacy includes not only general skills (information retrieval skills, information tool technical operations, etc.), but also special abilities (personal psychological characteristics that complete information activities with information awareness, knowledge, etc.). It can be seen that the information literacy of college students in this period is considered to be "a comprehensive performance internalized in the heart and externalized in the form".

\subsection{Under the $4 G$ environment: improve the overall information literacy of college students}

Compared with $3 \mathrm{G}$ technology, $4 \mathrm{G}$ technology has been greatly improved in data rate, service type, and transmission mode, realizing the circulation of information between different fields. ${ }^{[5]}$ The learning style of college students has evolved from a single and fixed traditional learning to a multi-dimensional, mobile and three-dimensional learning. In a learning society where everyone learns, learns everywhere, and can learn from time to time, mastering the learning ability cantered on information literacy has become the primary task of college students. ${ }^{[6]}$ Based on this, the "what and what" of college students' information literacy has become the content of in-depth discussion by researchers. Existing studies have found through largescale questionnaire surveys that the information literacy of college students is far from what it should be. The overall information literacy of college students is not high, the information awareness is strong, the information analysis ability is weak, the information ethics level needs to be improved, and the internal differences are large. ${ }^{[7]}$ This is obviously contrary to the original intention of proposing information literacy. At this stage, college students' information literacy highlights the "view of literacy", which emphasizes that college students should effectively and legally use information to solve practical problems and establish healthy and positive information values. All college students should demonstrate good moral cultivation in real situations. And legal awareness.

\section{THE EVOLUTION OF THE CONNOTATION OF COLLEGE STUDENTS' INFORMATION LITERACY IN THE 5G ENVIRONMENT}

\subsection{Value concept: realize information quality from information}

College students have a certain awareness of information sensitivity, information update awareness, and information dissemination awareness, and can preemptively occupy information and make good use of information resources, which will become the advantage of college students in the competition for social talents. However, with the support of 5G technology, information dissemination will be profoundly rewritten, and the torrent of information will flow into the lives of college students at an unprecedented speed. So how can college students "sweep" it into a trickle? In the $5 \mathrm{G}$ era of "information comes from the heart", college students can only better meet future challenges only with good information quality. Information quality is a prerequisite for college students to establish correct information values. It is a good quality in the process of receiving and applying information, including information perception, information needs, critical thinking, and values. Among them, critical thinking has become the key to determining the quality of information. If college students lack a certain ability to discern and judge information, and disseminate information regardless of true and false information, it will seriously hinder the normal order of social life and affect the development of information quality. Therefore, the cultivation of college students' information quality is the fundamental driving force to promote the advancement of college students' information literacy in the $5 \mathrm{G}$ environment. 


\subsection{Curriculum reorganization: from single major learning to multiple integration exploration}

Improving the curriculum system and updating knowledge content has become an important external factor in the cultivation of college students' information literacy. At present, the information literacy of college students does not run through all the professional curriculum systems, and even the information literacy of some majors still depends on the library. In the professional course study, only multimedia presentation teaching and PPT study report are used, which is believed to achieve the cultivation of information literacy. This kind of curriculum has led to large internal differences in information literacy among college students, and uneven information literacy levels. Obviously, colleges and universities are important bases for college students to learn, and curriculum reorganization is an urgent need to change. According to the meaning and characteristics of information literacy in the $5 \mathrm{G}$ environment, it is deeply integrated with the knowledge learning and practical inquiry of professional courses to improve the curriculum system and update the knowledge content, so as to better cultivate the information literacy of college students.

\subsection{Deep learning: from information knowledge to information wisdom}

In any society, knowledge is used to guide and guide life practice, while wisdom is the ability to solve problems based on the existing knowledge system. In the past, the concept of information knowledge was an instrumentalist concept of "getting it and using it without asking for a deep understanding", emphasizing the knowledge and experience accumulated by people using information technology tools, expanding information dissemination channels, and improving the efficiency of information exchange. While college students are gradually adapting and getting used to the convenience of $4 \mathrm{G}$ Internet, inertia has also begun to sprout. Some college students are unwilling to take the initiative to think to solve problems, "Baidu" has become the norm, and even become a kind of dependence. As a result, the information knowledge of college students has evolved into a simple search for Baidu search information. The information wisdom in the $5 \mathrm{G}$ environment cultivates the humanistic concept of "searching for the roots of the knowledge to apply it", constructing a knowledge system autonomously by means of deep learning, paying attention to in-depth exploration of the essence of information knowledge, and focusing on applying information knowledge to real situations In the middle, it highlights the information wisdom formed by college students in practical applications. In the $5 \mathrm{G}$ environment, in the face of personalized information resources pushed by users, college students should establish a concept of zero storage and integration. They should not become unidentified information and knowledge porters, but producers of deep learning information wisdom. The information is thoroughly explored, analysed, and sorted, and finally formed an internalized and personal wisdom system.

\subsection{Digital humanities: from information ethics to information ethics}

As a fundamental factor that restricts the overall level of information literacy, information ethics can regulate and restrict people's information behaviour and activities, and become an important criterion for judging the level of information literacy. The information moral level of college students directly reflects the level of their information literacy. At present, $5 \mathrm{G}$ is a strong technical support and technology empowerment opens the era of intelligent communication. How college students establish a benign interactive and dynamic balance relationship between "people and technology" highlights the importance of digital humanities. College students should view the impact of technological empowerment on the humanistic spirit from a dialectical philosophical perspective, and consider the relationship between the real world and the virtual world from a diverse cultural perspective, in order to establish a correct view of information ethics . College students need to maintain a "people-oriented, people-oriented" use of digital technology and tools, and realize the unity of cognition of instrumentality, value, and humanity. They should neither pursue "technology first" nor ignore the importance of digital humanistic spirit.

\section{CULTIVATION STRATEGIES FOR COLLEGE STUDENTS' INFORMATION LITERACY IN THE 5G ENVIRONMENT}

\subsection{Concept reshaping: from the orientation of information capture to the cultivation of critical thinking}

The information literacy concept of college students has become an endogenous driving force that affects their level. Ideas influence actions, and the reshaping of ideas plays a vital role in the cultivation of college students' information literacy. In the $5 \mathrm{G}$ environment, the flood of information will gush out if all gates are opened and flooded, and the flood of information will be difficult to carry. If college students only capture information, they do not have critical thinking and dialectical skills, and too much information will take up too much time and they will not be able to capture effectively. Critical thinking is not a concept that has never been mentioned in the development of information literacy, but it has been ignored by most 
students in the past. Critical thinking refers to the ability of college students to think and evaluate the credibility and usefulness of information resources in information activities. In other words, critical thinking requires college students to think systematically and dialectically in their own knowledge system. Based on this, concept reshaping has become the primary task of college students' information literacy training.

\subsection{Curriculum reorganization: from single major learning to multiple integration exploration}

Improving the curriculum system and updating knowledge content has become an important external factor in the cultivation of college students' information literacy. At present, the information literacy of college students does not run through all the professional curriculum systems, and even the information literacy of some majors still depends on the library. In the professional course study, only multimedia presentation teaching and PPT study report are used, which is believed to achieve the cultivation of information literacy. This kind of curriculum has led to large internal differences in information literacy among college students, and uneven information literacy levels. Obviously, colleges and universities are important bases for college students to learn, and curriculum reorganization is an urgent need to change. According to the meaning and characteristics of information literacy in the $5 \mathrm{G}$ environment, it is deeply integrated with the knowledge learning and practical inquiry of professional courses to improve the curriculum system and update the knowledge content, so as to better cultivate the information literacy of college students.

\subsection{Goal reconstruction: from theoretical knowledge as the leading factor to both knowledge, action and thinking}

Knowledge, action, and thinking go hand in hand, which is the key way for college students to form and improve their information literacy. Learning is knowing, which refers to the learning of theoretical knowledge, such as the principles of information tools, information communication knowledge, information interaction, etc.; practice is action, which refers to the experience of college students applying theoretical learning to practice; reflection is thinking, referring to It is a thinking activity of reflection and evaluation in the process of theory and practice. There will be the result of thinking but not learning. Information literacy has the characteristics of dynamic, complex, and procedural nature, and is in the process of dynamic changes due to the changes in mobile communication technology. The goal of cultivating information literacy of college students should move in accordance with the times, from theoretical knowledge as the leading factor to the simultaneous development of knowledge, action, and thinking.

\section{CONCLUSION}

In short, the coming $5 \mathrm{G}$ era is an era of great imagination and expectations, is a true sense of "People + Technology" convergence network. Therefore, college students need to rebuild their personal information literacy to meet the challenges and opportunities of the new $5 \mathrm{G}$ era.

\section{AUTHORS' CONTRIBUTIONS}

The title "AUTHORS' CONTRIBUTIONS" should be in all caps.

\section{ACKNOWLEDGMENTS}

This work is supported by Guizhou Normal University's 2019 "College Student Research and Training Program" Project, Guizhou Province (No.DK2019A061).

\section{REFERENCES}

[1] Peter Senge. The fifth practice [M]. 2nd edition. Guo Jinlong, translated. Shanghai: Sanlian Bookstore, 1998: 7.

[2] Jin Guoqing. Overview of Information Literacy Education in the Information Society[J]. Library and Information Service, 1995(06): 52-55.

[3] Guo Chaoming. The connotation and cultivation of information literacy in the information age $[\mathrm{J}]$. Audio-visual Education Research, 2007(11): 1619.

[4] Ming Hua, Lin Zhong, Luo Lei, Huang Silin. International Comparison of the Connotation and Structure of Information Literacy[J]. Journal of Beijing Normal University (Social Science Edition), 2019(02): 59-65.

[5] Haifeng, Wang Wei. The form of online collaborative learning in the $5 \mathrm{G}$ era: characteristics and models $[\mathrm{J}]$. China Audio-visual Education, 2019(09): 31-37+47.

[6] Zhong Zhixian. Facing lifelong learning: the connotation, evolution and standard of information literacy[J]. China Distance Education, 2013(08): $21-29+95$

[7] Qi Hangyu. Investigation and analysis of the status quo of college students' information literacy [D]. Heilongjiang University, 2016. 